\title{
A Rare Form of Protostylid: Review of Literature and Case Reports
}

\author{
Anand L. Shigli ${ }^{1}$, Sangeeta P. Wanjari², and Ruchi Ahuja ${ }^{1}$ \\ ${ }^{1}$ Department of Pedodontics and Preventive Dentistry, ${ }^{2}$ Department of Oral and Maxillofacial Pathology, \\ Modern Dental College and Research Centre, Indore, Madhya Pradesh, India.
}

ABSTRACT Human teeth possess an active cingular zone that serves as the point of origin for specific accessory cusps. The term protostylid or protoconid is used for any additional cusps on the buccal surface of maxillary and mandibular premolars and molars. Their occurrence in maxillary and mandibular deciduous and permanent dentition is discussed in the literature. This article presents a review of literature in relation to formation of the protostylid, and two cases of prominent protostylids are described, one each in the deciduous and permanent dentitions. Dental Anthropology 2010;23(1):28-31.
The protostylid exhibits a range of morphological expression ranging from a pit to a prominent cusp. However, its most common form is a surface irregularity (Dahlberg, 1963; Mayhall, 1979). Human teeth possess an active cingular zone that serves as the point of origin for specific accessory cusps (Butler, 1956). In the maxilla, this zone is active primarily on the lingual surfaces of the anterior teeth whereas in the molars, lingual tubercles and Carabelli's trait are expressed. The mandibular teeth are less likely to exhibit development from the lingual cingular zone, while a cingular trait of the lower molars, the protostylid, is sometimes present on the buccal surface of the mesiobuccal cusp. Simons (1972) points out that a correlation exists in pongids between well-developed lingual cingula of the upper molars and buccal cingula of the lower molars. This suggests that the Carabelli's traitprotostylid association in the human dentition reflects a long-term developmental relationship in hominoid phylogeny (Scott, 1978). The protostylid is also more frequent in early hominid species like those from the genus Australopithecus than in later Homo species. Among Australian Aborigines, the remarkable characters include those termed the "Mongoloid dental complex" (Hanihara, 1966, 1967, 1968, 1970) and Carabelli's cusp. The Mongoloid dental complex is composed of five crown characters, namely shovel-shape in the maxillary central incisors, cusp six, cusp seven, deflecting wrinkle, and protostylid on the mandibular first molars. This suite of characteristics is similar for deciduous maxillary incisors and mandibular second molars (Hanihara 1970).

Hanihara (1967) stated the protostylid occurs more frequently on the primary than permanent molars. According to Dahlberg (1950) and Hanihara (1961), whenever the protostylid is present on a permanent molar the trait was present on the primary second molar. However, the reverse situation does not always occur (Tongkoom, 1994). Hanihara (1961) provides a classification consisting of seven grades of the protostylid (Table). The protostylid also can occur on the primary mandibular second molars (Tongkoom, 1994).

This cingular feature, which was first reported by Bolk (1916), is seen most frequently on the buccal surface of the mesiobuccal cusp of both primary and permanent molars, so an additional cusp on the buccal surface of a molar is referred to as a paramolar tubercle, or Bolk's cusp (Tongkoom, 1994). Broom (1937) described the protostylid feature on "a rudimentary external cingulum." Dahlberg (1945) later proposed the term protostylid or parastyle for any anomalous cusp on the buccal surface of maxillary and mandibular premolars and molars (Goaz and Miller, 1966). Dart (1948) described the feature on a molar as "a laterally-disposed enamel ridge" separated from the protoconid by a cingular furrow. Dahlberg (1950) also noted that "although the cusp had its origin as an expression of the cingulum, it is a unit structure, an entity in itself and definitely unlike the continuing cingular eminence seen on the gorilla and other anthropoids."

The Arizona State University Dental Anthropology System (ASUDAS), which was devised for the analysis of modern human teeth, defines the protostylid as "a secondary groove that extends mesially from the buccal groove and which culminates in teeth with a marked expression of the protostylid, as a cusp with a free apex" (Turner et al., 1991). Turner et al. (1991) described it as "a paramolar cusp found on the buccal surface of the protoconid that is normally associated with the buccal groove." As noted by Hlusko (2004), the terms

Correspondence to: Anand L. Shigli, Department of Pedodontics and Preventive Dentistry, Modern Dental College and Research Centre, Gandhi Nagar, Airport Road, Indore - 453112, Madhya Pradesh, India.

Email address: shigsanand@rediffmail.com 
TABLE 1. Hanihara's (1961) classification is composed of seven grades of protostylid forms
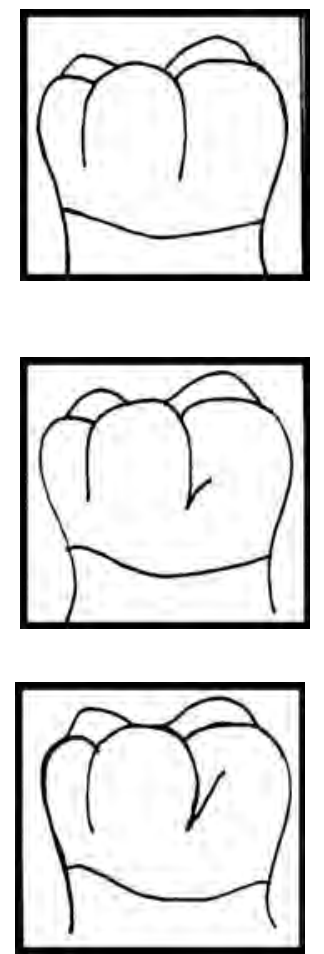

Grade 2: The divergence of the mesiobuccal groove is evident

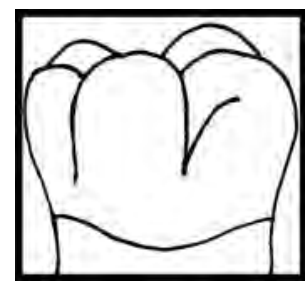

Grade 3: The two branches of the mesiobuccal groove are more strongly developed than in grade 2. A small triangular area with its tip downward occurs between the branches of the buccal groove

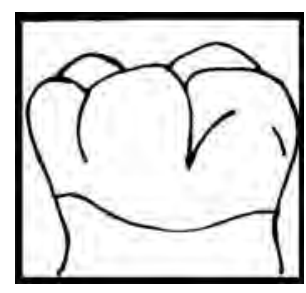

Grade 4: A shallow groove appears at the mesial corner of the buccal surface. The area between this groove and the mesial branch of the mesiobuccal groove bulges slightly and gives a triangular shape with its tip upward.

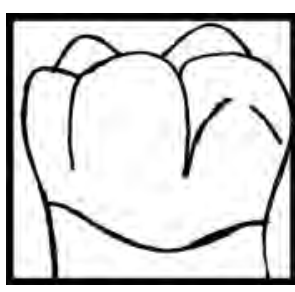

Grade 5: The triangular area is more strongly developed than in grade 4 .

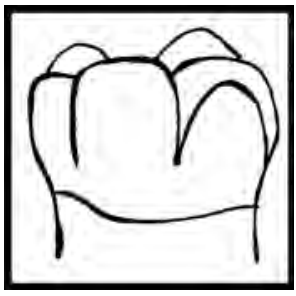
Grade 6: The protostylid is strongly developed so that the tooth seems to have an extra cusp on the buccal surface of mesiobuccal cusp. "protostylid" and "protoconidal cingulum" have been used interchangeably when describing features the buccal surface of hominin lower molars.

The prevalence of the protostylid varies with race (Dahlberg, 1963). It may be present in up to $40 \%$ of a population. The protostylid can occur with or without Carabelli's trait on the maxillary molars of Arctic people. The Carabelli trait frequently appears in Caucasoids. Like Carabelli's trait, the protostylid has both a similar range of morphological variation and frequency of forms (Turner, 1967). Hanihara (1968) reported a high frequency of this character in Pima Indians. Suzuki and Sakai (1954) found fairly frequent appearance of the protostylid in the mandibular molars of Japanese. In Mongoloid groups, the protostylid trait occurs in more than $40 \%$ of individuals, while in non-Mongoloid populations the prevalence is generally below $20 \%$.

\section{CASE REPORTS}

The following are case reports of two patients who visited the Department of Pedodontics and Preventive Dentistry of Modern Dental College and Research Centre, Indore, Madhya Pradesh, India.

The first case was a 14 year old girl with the chief complaint of decay in right and left lower back teeth. There was no history of pain or any discomfort, and she had no significant health history. Examination revealed an unusual accessory cusp in relation to the mesiobuccal cusp of the lower first permanent molars, which also exhibited a four cusp pattern (Figs. 1-3). This accessory cusp is grade 6 using Hanihara's (1961) classification (Table). The protostylid was strongly developed, giving the appearance of an extra cusp on the buccal surface. There also was a prominent cusp of Carabelli on the upper first permanent molars. The lower second premolars showed a Y-shape groove pattern.

The second case was an 11 year old girl with the chief complaint of a white spot on her upper left front tooth, and she wanted to have her teeth cleaned. She had no significant medical or dental history. Examination revealed that the patient had Turner's hypoplasia on the permanent maxillary left central incisor. An accidental finding was an accessory cusp (Fig. 4) on the mesiobuccal cusp of the deciduous maxillary right first molar classified as grade 6 using Hanihara's classification, and a pronounced bulge similar in relation to deciduous maxillary left first molar classified as grade 4 of the same (Table).

\section{DISCUSSION}

The protostylid forms during the morphogenetic phase of tooth formation, before the onset of dentinogenesis or amelogenesis. The fact that, it is actually the beginning of a cusp formation can be established by the shape of the enamodentin junction (EDJ) beneath it. These are considered outer enamel surface (OES) traits that are the 


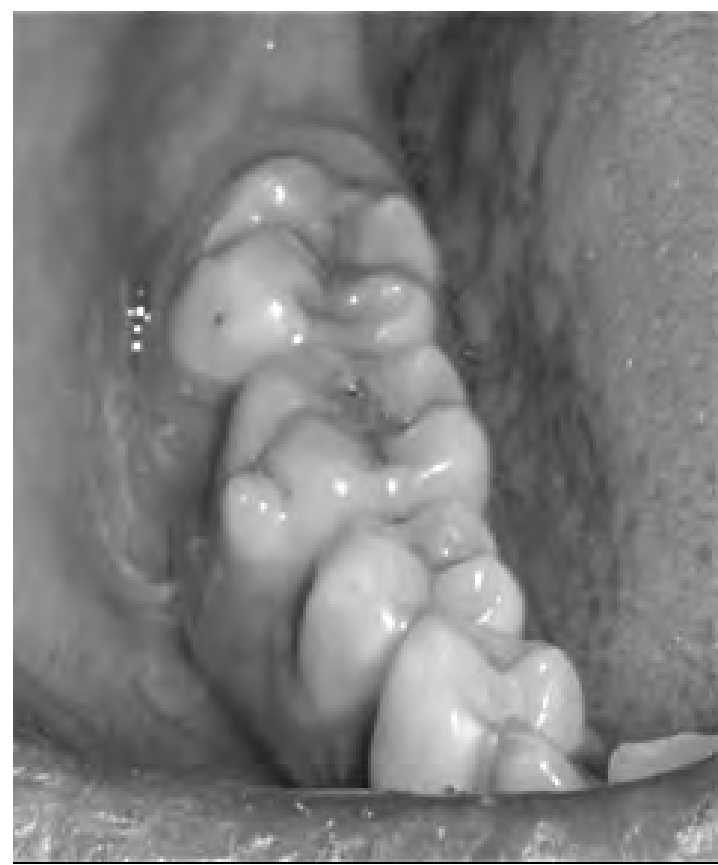

Fig. 1. Protostylid in relation to mesiobuccal cusp of permanent mandibular right first molar.

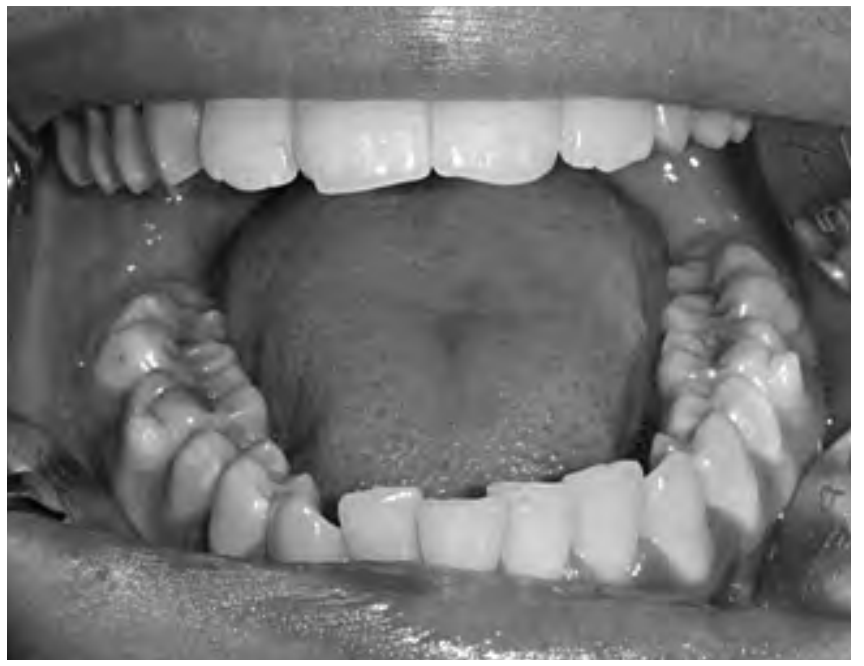

Fig. 3. Bilaterally appearing protostylid on the mandibular permanent first molars.

result of enamel being laid down over a template in the membrana preformativa during the formation of the tooth crown (Butler, 1956). In mature teeth the shape of this membrane persists as the EDJ. Although this informative morphology is preserved at the EDJ may not always be present at the OES due to a lack of correspondence between the two surfaces (due to differential enamel deposition) or due to dental attrition (Skinner et al., 2009).

The location and the morphology of protostylid pits make them similar to occlusal fissures. Both features open at the bottom of the groove between the two cusps,

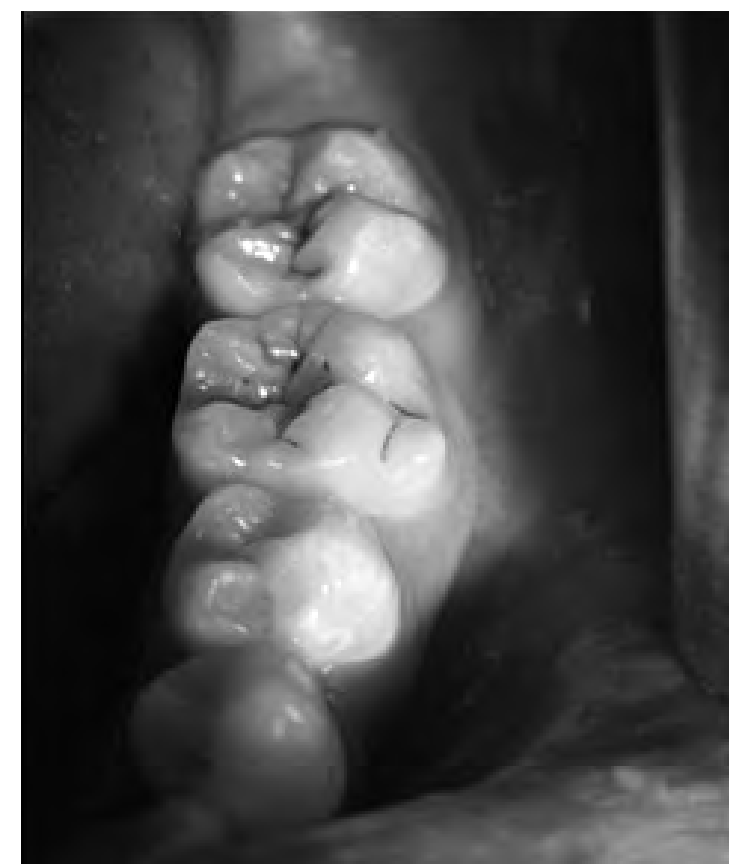

Fig. 2. Protostylid in relation to mesiobuccal cusp of permanent mandibular left first molar.

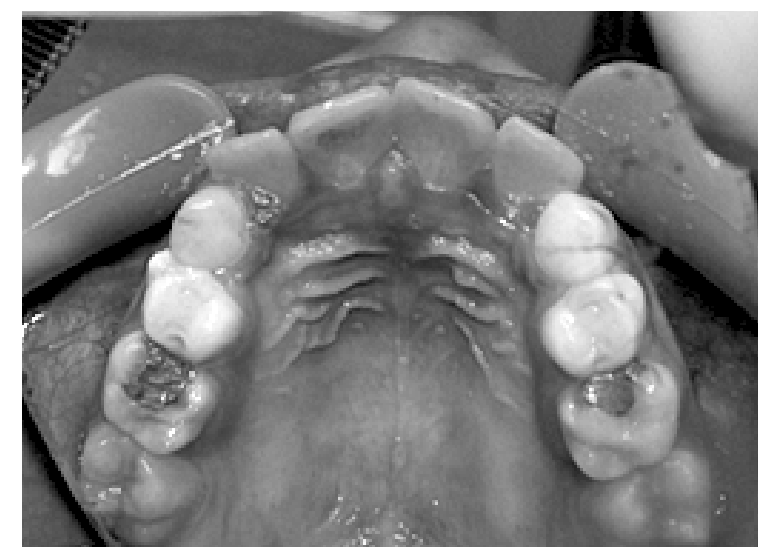

Fig. 4. Bilaterally appearing well-pronounced protostylid on deciduous maxillary left and right first molar.

and they both extend to the most concave point of the enamodentin junction. The depth of the normal fissure depends on the distance between two growth centers (Awazawa et al., 1989), which is on a concavity of the EDJ, and the same probably is true for protostylid pits. Soon after the beginning of amelogenesis at this site, the enamel organ becomes increasingly constricted because of the concave EDJ. Eventually, amelogenesis at the foot of the pit ceases and the ameloblasts lose their Tomes' processes and form a layer of surface aprismatic enamel (Gaspersic, 1993). 
The protostylid has been viewed both as an accessory cusp and as a remnant of a cingulum (i.e., a crestal feature). This distinction is relevant to considerations of whether the feature is a cusp or a crest, but this depends on the definition of a cusp. The primary cusps of all primate teeth have a dentin horn, which forms early in the development of the tooth crown on the surface of the inner enamel epithelium, and is subsequently covered by enamel. This is also the case for the majority of accessory cusps, such as cusp six and cusp seven (Skinner et al., 2008), and even small features such as marginal ridge tubercles on upper molars and the mammelons present on unworn incisors (Kraus and Jordan, 1965). Only in rare circumstances in extant hominoids and fossil hominins are there "enamel-only" cuspules (i.e., small cusps with no underlying dentin horn). Thus, for the purpose of defining the protostylid trait a structure defined as a cusp should exhibit an underlying dentin horn at the EDJ surface. The protostylid pit may lie between a large protoconid and a nearly negligible protostylid consisting only of dentin core (Gaspersic, 1993).

\section{CONCLUSION}

The protostylid and Carabelli's trait was found to co-occur in the two cases described. This combination is interesting because these traits occur on homologous cusps in opposite jaws (Tongkoom, 1994). The similarity in form and position of this structure in contemporary man and in prehistoric forms is considered as evidence of a relationship between these groups.

\section{LITERATURE CITED}

Awazawa Y, Hayashi K, Awazawa I, Tobari H. 1989. Pathomorphological study of the supplemental groove. Bull Group Int Rech Sci Stomatol Odontol 32:145-156.

Bolk L. 1916. Problems of human dentition. Am J Anat 19:91-148.

Broom R. 1937. Discovery of a lower molar of Australopithecus. Nature 140:681-682.

Butler PM. 1956. The ontogeny of molar pattern. Biol Rev 31:30-70.

Dahlberg AA. 1945. The changing dentition of man. J Am Dent Assoc 32:676-690.

Dahlberg AA. 1950. The evolutionary significance of the protostylid. Am J Phys Anthropol 8:15-25.

Dahlberg AA. 1963. Analysis of the American Indian dentition. In: Brothwell DR, editor. Dental anthropology. Oxford: Pergamon, p 149-177.

Dart RA 1948. The adolescent mandible of Australopithecus prometheus. Am J Phys Anthropol 6:391-411.

Gaspersic D. 1993. Morphology of the most common form of protostylid on human lower molars. J Anat 182:429-431.
Goaz PW, Miller MC. 1966. A preliminary description of the dental morphology of the Peruvian Indian. J Dent Res 45:106-119.

Hanihara K. 1961. Criteria for classification of crown characters of human deciduous dentition. J Anthropol Soc Nippon 69:27-45.

Hanihara K. 1966. Mongoloid dental complex in deciduous dentiton. J Anthropol Soc Nippon 74:9-20.

Hanihara K. 1967. Racial characteristics in the dentition. J Dent Res 46:923-926.

Hanihara K. 1968. Morphological pattern of deciduous dentition-the Japanese American hybrids. J Anthropol Soc Nippon 76:114-121.

Hanihara K. 1970. Mongoloid dental complex in the deciduous dentition, with special reference to the dentition of the Ainu. J Anthrop Soc Nippon 78:3-17.

Hlusko LJ. 2004. Protostylid variation in Australopithecus. J Hum Evol 46:579-594.

Kraus BS, Jordan RE. 1965. The human dentition before birth. Philadelphia: Lea and Febiger.

Mayhall JT. 1979. The dental morphology of the Inuit of the Canadian Central Arctic. Ossa 6:199-218.

Scott GR. 1978. The relationship between Carabelli's trait and the protostylid. J Dent Res 574:570-575.

Simons EL. 1972. An introduction to man's place in nature: primate evolution. New York: Macmillan, p 242.

Skinner M., Wood BA, Hublin JJ. 2009. Protostylid expression at the enamel-dentine junction and enamel surface of mandibular molars of Paranthropus robustus and Australopithecus africanus. J Hum Evol 56:76-85.

Skinner MM, Wood BA, Boesch C, Olejniczak AJ, Rosas A, Smith TS, Hublin JJ. 2008. Dental trait expression at the enamel-dentine junction of lower molars in extant and fossil hominoids. J Hum Evol 54:173-186.

Suzuki M, Sakai T. 1954. On the "protostylid" of the Japanese. Zinruigaku Zassi 63:81-84.

Tongkoom S. 1994. The prevalence of dental anomalies in Chinese children. Thesis, Masters in Dental Surgery, Department of Children's Dentistry and Orthodontics. Hong Kong. Retrieved on September 16, 2009. http:// sunzi.lib.hku.hk/hkuto/view/B31953980/ft.pdf

Turner CG II. 1967. Dental genetics and microevolution in prehistoric and living Koniag Eskimo. J Dent Res 46:911-917.

Turner CG II, Nichol CR, Scott GR. 1991. Scoring procedures for key morphological traits of the permanent dentition: the Arizona State University Dental Anthropology System. In: Kelley M, Larsen CS. editors. Advances in dental anthropology. New York: Wiley-Liss, p. 13-31. 